\title{
A Qualitative Exploration Of Parents' Experience And Perceptions Comparing Individual To Group Sports In Young People With Autism Spectrum Disorder.
}

Daniel Vella Fondacaro ( $\sim$ dan.vella.fondacaro@gmail.com )

Mount Carmel Hospital, Mental Health Malta https://orcid.org/0000-0002-4025-9581

Nigel Camilleri

Mount Carmel Hospital, Mental Health Malta

\section{Research article}

Keywords: 1) Autism spectrum disorders, 2) Parent-child interaction, 3) Sports Activity, 4) Young people,

5) Technology.

Posted Date: July 29th, 2020

DOl: https://doi.org/10.21203/rs.3.rs-48467/v1

License: (c) (1) This work is licensed under a Creative Commons Attribution 4.0 International License.

Read Full License 


\section{Abstract}

Background: Young people (YP) with autism spectrum disorder (ASD) may prefer individual to group physical activity (PA). Levels of PA may differ with disorder severity and age. This study explores parents' experiences with YP suffering from ASD when choosing between group and individual PA.

Method: Retrospective case note reviews identified 701 new referrals received by the National Child and Young People's Services, Malta, between 2016 to 2017. Of them, 24 received a diagnosis of ASD without co-morbidities and 10 were chosen via purposive random sampling. An 11-component semi-structured interview guide was created specifically for use in this study. Parents were interviewed and a thematic analysis was carried out.

Results: Only one young person carried out PA which met the World Health Organisation recommendations. More parents (group only: $n=3 ; 30 \%$, both: $n=6 ; 60 \%$ ) preferred group PA for their children, while more YP (individual only: $n=4 ; 40 \%$, both: $n=4 ; 40 \%$ ) preferred individual PA. Parents described both group and individual PA having benefits. Most parents felt 'misrepresented' and wanted to have more ASD-friendly sports facilities developed in for YP in Malta. Long hours of screen time was also a major parental concern. Younger age and more severe ASD were associated with higher levels of PA. Lower levels of PA, older age and milder ASD were associated with higher use of technology.

Conclusion: This study reported on the parents' perceptions on PA and discusses a possible link between ASD severity, PA, age and technological devices. The recommendations from this study are aimed at informing the development of sport services to be outsized as a form of therapy in Malta.

\section{Key Practitioner Message}

- PA has a positive psychosocial impact on the mental health of YP, especially on their self-esteem and social interaction skills.

- YP with ASD enjoy group activities less than neurotypically developing YP.

- Parents of YP with ASD felt overwhelmed by the absence of available sports facilities and misrepresented by service developers.

- Younger age and more severe ASD were associated with higher levels of PA. Lower levels of PA, older age and milder ASD were associated with higher use of technology.

- There is a need for the consideration of the development of ASD-friendly sports facilities and a robust sport therapy mental health services within our communities.

\section{Introduction}


It is widely accepted and evidenced through various publications within the literature that physical activity (PA) has a positive psychological and social impact on the mental health of young people (YP), especially on their self-esteem and social interaction skills (Eime et al., 2013). The World Health Organisation (WHO) suggests that healthy YP aged 5-17 years should carry out at least sixty minutes of moderate-to-vigorous-intensity PA daily (WHO, 2010). Despite widespread promotion of an active lifestyle, YP have become less physically active in recent years (Boreham \& Riccock, 2001).

PA helps YP with autism spectrum disorder (ASD) improve their social communication and interaction skills by providing opportunities to socialise and meet new people in group activities (Walker, Barry \& Bader, 2010). PA programmes with individual activities were also noted to have several advantages in YP with ASD as it can be adjusted to the individual's specific needs (Schultheis, Boswell \& Decker, 2000). Choosing between group and individual PA often becomes a topic of debate amongst parents in child and adolescent mental health services. YP with ASD enjoy group activities less than neurotypically developing YP (Stanish et al., 2015), and only tend to engage in more peer interaction as they grow older (Pan, 2009). YP might engage better in sports and PA if they choose the type of sports based on preference, rather than social norm or parent opinion (Pan \& Frey, 2006).

This study aims to assess PA levels in YP with ASD and to compare the effects of group and individual sports. The data was collected via semi-structured interviews with parents of YP with ASD which focused on experiences with their children in relation to their patterns of PA. The interviewer aimed to elucidate insights into the advantages and disadvantages of group and individual PA on the mental state and quality of life of their children.

\section{Method}

\section{Participants}

YP referred to the National Child and Young People's Services (CYPS) department, (Malta), between 2016 and 2017, who were diagnosed with ASD via the multimodal assessment as described by the NICEguidelines (UK), were recruited to this study. These YP were identified through a patient electronic database ( $n=701)$ and were selected for this study via purposive random sampling (Phase 1; Table 1). The inclusion criteria for this study; included: 1) A diagnosis of ASD as described by NICE guidelines and multidisciplinary team discussions, 2) YP from 5 to 17 years of age, 3) New case referrals to CYPS between 2016 to 2017. The exclusion criterion for this study included: 1) Having another psychiatric comorbidity together with an ASD diagnosis.

Through a retrospective case note review of the new case referrals, the author identified a total of 83 YP with a diagnosis of ASD. However, this list included YP with other co-morbid mental disorders. A more detailed case note review identified 24 YP with ASD as their only psychiatric diagnosis. The final sample for interviews ( $n=10$; Tables 1 \& 2) was chosen by random sampling (by lot). These YP were divided into groups according to their level of severity as per the Diagnostic and Statistical Manual of Mental 
Disorders, $5^{\text {th }}$ Edition (DSM-5; American Psychiatric Association, 2013). The levels of severity ranged from Level 1 ('requiring support') to Level 3 ('requiring very substantial support). The parents of the YP in the final sample were then recruited for participation (P1 to P10) in an interview.

All data were stored anonymized in a password-protected excel spreadsheet.

Table 1: Phase 1; The selection process.

\begin{tabular}{|c|c|c|}
\hline \multicolumn{2}{|c|}{ CYPS case referrals 2016-2017 } & $\mathrm{n}=701$ \\
\hline \multicolumn{2}{|c|}{ ASD +/- comorbid mental disorders } & $\mathrm{n}=83$ \\
\hline \multicolumn{2}{|l|}{ ASD } & $\mathrm{n}=24$ \\
\hline \multicolumn{2}{|c|}{ Study sample (random sampling) } & $\mathrm{n}=10$ \\
\hline \multirow[t]{3}{*}{ ASD severity } & Level 1 & $\mathrm{n}=2$ \\
\hline & Level 2 & $\mathrm{n}=4$ \\
\hline & Level 3 & $\mathrm{n}=4$ \\
\hline
\end{tabular}

Table 2: Selected sample for parent interview

\begin{tabular}{|lll|}
\hline YP ID Code & Age & ASD Severity \\
\hline YP1 & 10 years & Level 2 \\
\hline YP2 & 5 years & Level 3 \\
\hline YP3 & 8 years & Level 1 \\
\hline YP4 & 5 years & Level 2 \\
\hline YP5 & 8 years & Level 3 \\
\hline YP6 & 5 years & Level 2 \\
\hline YP7 & 5 years & Level 3 \\
\hline YP8 & 5 years & Level 3 \\
\hline YP9 & 9 years & Level 1 \\
\hline YP10 & 8 years & Level 2 \\
\hline
\end{tabular}

Data Collection

Semi-Structured Interview Guide 
The interview guide was created purposely for this study by the researcher. A semi-structured interview process was chosen as it gave flexibility for the parents to elaborate on various topics which were not predetermined by the researcher. Readability testing was performed and the guide was found to be age appropriate. Translation and back-translation from English to Maltese was carried out by a University of Malta graduate in the Maltese language. The guide was initially piloted in a focus group and suggestions brought out by the group were then discussed with the study supervisor.

The interview included 11 questions which focused on the type and frequency of PA carried out by the YP, whether sports was important for the YP and their parents, the parents' opinion on what is ASD and the parents' and YP's preference between group and individual PA. The questions also focused on barriers and opportunities to perform PA, and the number of hours per week that the YP spent using technological devices such as television, video games or the computer/tablet. The guide included the Godin LeisureTime Exercise Questionnaire (GLTEQ), which is a validated questionnaire used to monitor for PA (Godin \& Shephard 1997). Parents filled in two sets of GLTEQ, one for themselves and one on behalf of their child.

\section{Focus Group}

A focus group discussion was carried out prior to the interviews. This was organised by two foundation year (FY) doctors currently in their psychiatry rotation. These were selected to reduce an observation bias which would have been created by the researcher. The interview guide was presented to three parents of YP with ASD from the list of CYPS referrals and feedback was gathered. This enabled assessment of acceptability of the questions being asked; in terms of content, clarity, relevance and completeness. An inter-rater exercise was also carried out and a consensus was reached between the two doctors in the focus group together with the researcher as an intermediary. .

\section{Interviewing Process}

Six mothers and four fathers of YP $(n=10)$ were interviewed. Interviews were carried out at the CYPS department (Malta) and the Psychiatric Unit at Mater Dei General Hospital (Msida, Malta) in May 2018. Both verbal and written consent were obtained, and all interviews were digitally recorded and transcribed verbatim. Participation was entirely voluntary; every participant was allowed to decline at any point within the interview without giving a reason and no incentives were promised.

\section{Data Analysis}

A thematic analysis was carried out using the codes created from the transcripts (Braun \& Clarke, 2006).The initial themes were reviewed, defined and organised into final themes.

In addition to the thematic analysis, simple analysis of the rest of the data (nominal or quantitative) was carried out. This included frequency of PA and use of technological devices (hours/week), number of parents/YP preferring group PA or individual PA, number of parents who agree or disagree that opportunities for their children to perform sports/physical exercise are readily available, GLTEQ scores for 
parents and YP, and levels of PA tabled against age, level of ASD severity and use of technological devices.

\section{Ethical Information}

The application for an ethical opinion was submitted on the $24^{\text {th }}$ December 2017. A favourable ethical opinion (ref: HEC 14/17) was received from Health Ethics Committee (HEC), Ministry of Health Government of Malta (date: $29^{\text {th }}$ January 2018). Research governance approval was granted by the Chairman of the Department of Psychiatry, Malta. Both verbal and written consent were obtained.

\section{Results}

\section{Thematic Analysis Results}

This thematic analysis process generated 169 initial codes. These codes were reviewed and re-grouped into 21 initial themes, which were re-grouped further into 7 final themes (Table 3).

Table 3: Themes generated from this thematic analysis

\section{9 initial codes}

21 initial themes

7 final themes

1. Group sports, social interaction and communication

2. Individual sports, self-esteem and venting one's frustration

3. Lack of public awareness, opportunities and resources
4. Lack of motivation in sports

5. Physical and mental burden on relatives

6. General improvement in physical and mental health

7. Technology and the Potential for Internet addiction

\section{Group Sports, Social Interaction and Communication}

Almost all parents $(n=9)$ described the difficulties their children experienced with social interaction and communication, most especially when meeting new people $(n=8)$ :

'So, I think, erm, what he suffers most is to make friends... He finds it very difficult to write. He finds it difficult to, erm, communicate with other children because he does not talk yet.'(P2).

Several parents $(n=4)$ also spoke about their child's confidence and how this relates to the importance of making friends. They referred to their child's social interaction as a passive and repentant one, i.e. waiting 
for others to invite them to play, rather than actively taking part in group play:

'Maybe sometimes someone tells him, 'Come play with me!'. And he goes, but only for a while. But they must tell him. He's not going to go himself...'(P4).

Three parents described preferring group sports to individual sports for their children; six parents explained that both group and individual sports are important in YP with ASD, while only one parent preferred individual to group sports for her child. Some parents $(n=2)$ believed that group sports help YP with ASD interact better by exposing them to other children with different characteristics, while others $(n=6)$ felt that group sports increases motivation and social drive:

'It helps you integrate more as a group, eh. In today's society, you must function as a group...'(P4).

'I think it's better if he's in a group. Because they will have that small push... It's like, in a group you're not alone...'(P10).

\section{Individual Sports, Self-Esteem and Venting One's Frustration}

Parental interviews reported that four YP preferred individual sports to group sports, four YP prefer both group and individual sports, while two YP preferred group to individual sports. Most parents explained that individual sports have some benefits as well:

'...then maybe because it's individual sports, it muffles his shyness and boosts his self-esteem basically.' (P1).

'So individual sports is important because it gives you confidence, and that kind of, within yourself... esteem.'(P7).

Parents $(n=3)$ also mentioned the importance of giving children an active role in choosing their type of sport as it improves the child's willingness to attend:

'...if he does not know how to play football, it's useless putting him in a football match alongside other children. He does not know how to play, so he won't integrate or else runs out.'(P2).

Some parents $(n=3)$ believed that individual sports may serve as a way to tackle hyperactivity and help cope with anxiety in YP with ASD:

'The more he runs, the more he takes out his frustration.'(P1).

\section{Lack of Public Awareness, Opportunities and Resources}

Awareness, stigma and resources were common topics mentioned during the interviews. Most parents $(n=6)$ spoke about the lack of public awareness and the negative effects of stigma in ASD:

'People, eh, they make it even more difficult... Because there is no awareness. I was one of them...'(P10). 
Two parents felt that awareness is slowly improving, especially between YP themselves:

'Back in the days, I'm 35, we never used to see what we see today. We used to see someone like this and laugh at him.' '(P7)

Parents $(n=7)$ spoke about the lack of opportunities and suitable resources in Malta. They spoke about the need for more ASD-friendly sports facilities to be made available for YP to help with their well-being:

'... whether they are teachers or coaches, whatever... that are not qualified for the job, with autism.'(P7).

'...for example, my nephews and nieces go to a lot of sports and drama. But I can't register my son because he needs someone one-to-one.'(P2).

Parents $(n=6)$ spoke in favour of grouping YP with ASD in special groups to facilitate participation. Others $(n=2)$ preferred mixed ability groups as it helps YP with ASD learn socially appropriate behaviours from other neurotypically developing children:

'I think he needs to adapt to the sport. He has to be able to cope. It doesn't matter if he doesn't manage immediately...'(P3).

\section{Lack of Motivation in Sports}

Parents $(n=3)$ also spoke about the lack of motivation that their children experience when doing PA and how this holds them back from participating in any further PA. They also spoke about how motivation is bolstered by encouragement from peers:

'He does karate, and he started getting tired. Yes, yes. He tries, let me say that, but, erm, it's like when he sees difficulty, he stops. He gives up very easily.'(P3).

Parents $(n=4)$ associated the child's lack of motivation with the home environment. They explained that their children participated more in PA when it was organised at school rather than at home:

'But the learning support assistant does a lot more with them than us. She tells us stuff that we can never imagine him doing at home. He does them at school...'(P10).

\section{Physical and Mental Burden on Relatives}

Parents $(n=5)$ felt that parenting a child with ASD creates a lot of physical and mental stress:

'I have fibromyalgia as well! So, I have my own problems. It might be that the fibromyalgia came out because of these children.'(P6).

Some parents $(n=3)$ reported that sports facilities are located too far away from their residential home. They suggested an even geographical distribution, making it convenient for all to attend. Others $(n=2)$ reported that they could not find the time to do their own PA or to take their children to sports facilities: 
'Not, for example, in Valletta... but in the South. Because like I'm telling you, to go to the North with two children, it is a bit difficult for me.'(P8).

I have a spinal condition, and I'm going to physiotherapy, and I'm not finding the time to do them. All I need is twenty minutes a day, and I'm not finding the time...'(P7).

\section{General Improvement in Mental and Physical Health}

All parents spoke about how ASD impacted their family lives. However, they reported that symptoms gradually improved with age:

'For example, he used to stay rotating the wheels of his toy cars I used to give him, all the time. Now he reduced these habits a lot, thank God.'(P10).

Parents $(n=6)$ also reported that ASD symptoms improved with PA. Some explained that this might be due to the calming effect of PA and the promotion of a healthy lifestyle:

'It's good for physical health, and mentally as well I think, because I think sports, at the same time, relaxes you as well. It's like you escape from life and the daily stresses.'(P4).

\section{Technology and the potential for Internet Addiction}

One of the main issues which concerned parents was the excessive number of hours which their children spent using technological devices. They felt that excessive screen time has a negative effect on YP's PA patterns and school performance:

'When he comes home, he does not move from his chair between three and eleven. Playing PlayStation. It's like I have a man who's hooked on wine, and I cannot take it away from his hands.'(P6).

Two parents spoke about the role technological devices have on their children's education. They explained that YP may use such technological devices to help them learn by using visual means:

'They watch YouTube. So, they rarely watch a film. But still, we always try to show her educational stuff as much as possible.'(P7).

\section{Other Results}

\section{Quantity of Physical Activity}

Only three parents reported that their child does extracurricular PA or sports which follow a weekly schedule. All ten participants were asked to fill in a GLTEQ for themselves and one for their children (Table 4).

Table 4: Results showing level of physical activity per week 


\begin{tabular}{|llllll|}
\hline & $\begin{array}{l}\text { Age } \\
\text { (Years) }\end{array}$ & $\begin{array}{l}\text { Level of } \\
\text { ASD } \\
\text { Severity }\end{array}$ & $\begin{array}{l}\text { YP performs sports/physical } \\
\text { activity every week (Yes/No) }\end{array}$ & $\begin{array}{l}\text { GLTEQ } \\
\text { Score } \\
\text { (Parent) }\end{array}$ & $\begin{array}{l}\text { GLTEQ } \\
\text { Score (YP) }\end{array}$ \\
\hline YP1 & 10 & Level 2 & No & 26 & 28 \\
\hline YP2 & 5 & Level 3 & Yes & 48 & 119 \\
\hline YP3 & 8 & Level 1 & Yes & 32 & 34 \\
\hline YP4 & 5 & Level 2 & No & 13 & 37 \\
\hline YP5 & 8 & Level 3 & No & 36 & 50 \\
\hline YP6 & 5 & Level 2 & No & 27 & 18 \\
\hline YP7 & 5 & Level 3 & No & 31 & 34 \\
\hline YP8 & 5 & Level 3 & No & 56 & 16 \\
\hline YP9 & 9 & Level 1 & No & 35 & 25 \\
\hline YP10 & 8 & Level 2 & Yes & 56 & 12 \\
\hline
\end{tabular}

The mean GLTEQ scores of both parents and YP were highest in level 3 ASD severity (42.75 and 54.75 respectively) and lower in Level 1 and Level 2 ASD severity (Table 5). The mean parent and YP GLTEQ scores of the younger group (35 and 44.8) were both higher than the older group (33 and 29.8) (Table 6).

Table 5: Results showing mean GLTEQ scores per level of ASD severity.

\begin{tabular}{|lll|}
\hline Level of ASD Severity & Mean GLTEQ (Parents) & Mean GLTEQ (YP) \\
\hline Level 1 & 33.5 & 29.5 \\
\hline Level 2 & 30.5 & 23.75 \\
Level 3 & 42.75 & 54.75 \\
\hline
\end{tabular}

Table 6: Results showing mean GLTEQ scores per YP age group.

\begin{tabular}{|lll|}
\hline YP Age Group (Median=6.5y) & Mean GLTEQ (Parents) & Mean GLTEQ (YP) \\
\hline Lower than median (Younger) & 35 & 44.8 \\
\hline Higher than median (Older) & 33 & 29.8 \\
\hline
\end{tabular}




\section{Group and Individual Physical Activity}

All parents agreed that PA is important for YP with ASD. Six parents reported that both group and individual sports are important, while three parents preferred group sports for YP with ASD. Only one parent preferred individual sport for his child. Parents were also asked whether their children themselves would prefer group or individual sports. They reported that four YP preferred individual PA, another four YP enjoyed both group and individual PA, while only two YP preferred group PA (Figure 1). Therefore, one can observe that there was a greater proportion of YP with ASD who preferred individual PA $(n=4)$ to group PA $(n=2)$.

\section{Time Spent Using Technology Devices}

The majority of the parents expressed their concern with the use of technology for long hours during the day, however other parents $(n=2)$ felt that this was used as a stress-coping mechanism. The mean use of technological devices (hours/week) decreased as the level of ASD severity increased; from level 1 (48 hours/week) to level 3 severity (15.125 hours/week) of ASD (Table 7). There was a higher use of technological devices in the older age group (34.6 hours/week) than in the younger age group (23.1 hours/week) (Table 8).

Table 7: Results showing the mean use of technological devices per severity of ASD.

\begin{tabular}{|ll|}
\hline Level of ASD Severity & Mean use of technological devices (hours/week) \\
\hline Level 1 & 48 \\
\hline Level 2 & 33 \\
\hline Level 3 & 15.125 \\
\hline
\end{tabular}

Table 8: Results showing the mean use of technological devices per YP age group.

\begin{tabular}{|ll|}
\hline YP Age Group (Median=6.5y) & Mean use of technological devices (hours/week) \\
\hline Lower than median (Younger) & 23.1 \\
\hline Higher than median (Older) & 34.6 \\
\hline
\end{tabular}

The mean use of technological devices per week was assessed in relation to PA by dividing the YP in two groups as per the GLTEQ scores (Median=31). The YP who performed less PA (lower GLTEQ score group - 37.5 hours/week) spent more time using technological devices compared to YP who performed more PA (20.2 hours /week) (Table 9). 
Table 9: Results showing the mean use of technological devices per GLTEQ score group.

\begin{tabular}{|ll|}
\hline YP GLTEQ Score (Median=31) & Mean use of technological devices (hours/week) \\
\hline Higher GLTEQ Score Group & 20.2 \\
\hline Lower GLTEQ Score Group & 37.5 \\
\hline
\end{tabular}

\section{Discussion}

To our knowledge this is the first study of its kind carried out in Malta. Given the robust methodology used to carry out this study, the results from this qualitative analysis can serve to inform service development for YP with ASD, and also serve as a platform for further research. One key finding from this study was a general lack of PA in YP with ASD. It also showed a general preference for individual PA in these YP. Parents showed significant concern with the long hours of screen time in their children routine. An interesting finding was the association between younger age, severity of ASD and higher levels of PA. Older age and milder ASD were associated with more time spent using technological devices.

Despite parents mostly (group only: $n=3 ; 30 \%$, both: $n=6 ; 60 \%$ ) preferring group sports for their children, more YP (individual only: $n=4 ; 40 \%$, both $n=4 ; 40 \%$ ) in this study preferred individual sports. This reaffirms the assertion that YP with ASD prefer staying alone and avoiding social situations (Pan, 2009). Parents reported that when the sport was chosen by the YP, attendance improved. This highlighted that sports should be 'based on preference, rather than socialization opportunities' (Pan \& Frey, 2006).

From the findings in this study, it was clear that parents reported low levels of PA in their children. Three parents reported regular weekly PA in their child, only one of which reported adequate weekly PA in line with WHO (2010) recommendations. This was not surprising given the increasing sedentary lifestyle in YP living in European countries due to their free time being spent using the Internet and technological devices (WHO, 2006). This was also highlighted in parental reports (Table 9); YP with ASD who did less PA spent more time using technological devices. Increased screen time was reported in YP with milder forms of ASD (Level 1) and older age groups. This might be related to better levels of cognitive ability in this group of YP (Czaya et al., 2006).

Seven parents in this study reported lack of opportunities for YP with ASD to carry out PA in Malta. There are several Maltese agencies, such as Sport Malta (Government of Malta) which have a directory of sport organisations and facilities where one might practice a sport (Sport Malta, 2015). Despite this, parents in this study argued that these facilities are not adequate for YP with ASD. To implement a national sports therapy service, one must consider the needs of the YP with ASD, the needs of their parents/caregivers and the needs of society in general. The lack of sports opportunities and well-adapted facilities might be due to the lack of general public awareness on ASD (Alsehemi et al. 2017); as also highlighted in this study's thematic analysis. Parents reported that sports facilities are located "too far away" or else they "do not find the time" for drop offs and picking up their children. It is especially difficult for people who 
rely on public transportation. Transporting YP with ASD in a car for long distances might be unsafe because the YP might suffer from melt downs or may try abscond from the car (Yonkman et al., 2013). Therefore, ideally sport therapy services should be distributed evenly across the island. This study raises the awareness that sports facilities should all be developed to cater for easy access and used by YP with ASD.

Another finding from this study is the increased PA levels in the most severe level of ASD. This might be explained by understanding the role of coping strategies in ASD and how PA helps with venting anxiety (Stonerock et al. 2015); also reported by parents above. PA might have also been reported to be higher in more severe ASD due to the greater effort by parents to try find alternatives to improve their child's psychosocial state through sports (Obrusnikova and Miccinello 2012). In fact, all parents in this study showed interest and motivation to improve their child's physical activity levels through sports. This shows a current disproportionation between national health resources and the service users' wants and needs.

Results from this study indicated that the younger group of YP with ASD was more physically active than the older group. Therefore, one can argue that PA was higher in the more vulnerable YP with ASD (severe ASD and younger age group). This might be due to higher impulsivity associated with ASD severity (Tureck et al. 2015) and younger age groups, thus driving YP to carry out more PA. Furthermore, it could be that with age, YP with ASD loose interest in physical activities and choose more sedentary forms of relaxation such as Internet use.

This study showed that the parents of YP with level 3 ASD (mean GLTEQ=42.75) carried out more PA than the parents of YP with level 1 and level 2 ASD (mean GLTEQ=33.5, 30.5). One may postulate that parents of YP with Level 3 ASD might be carrying out more PA than parents of YP with milder forms of ASD as they understand that PA is especially important for their own mental wellbeing, and for their children to improve their social skills (Obrusnikova and Miccinello 2012). Furthermore, the parents of more severe levels of ASD may be carrying out more PA as they need more free time due to their childrens' demands being higher.

\section{Bias}

Selection bias could have been introduced since the sample was taken only from the filing records of CYPS, and therefore excluded all those YP with ASD who attended private clinics across the Maltese Islands. However, this study did manage to select an appropriately varied sample of YP with ASD for a qualitative study, furthermore, it focused on improving the Maltese national health service. A potential observation bias was minimised by involving junior doctors when completing the interviews and carrying out an inter-rater exercise. All interviewers were previously unknown to the participants which further reduced a bias.

\section{Strengths and Limitations}


Using meticulous inductive thematic analysis techniques helped to avoid missing important details. Precautions were also taken to avoid a potential bias. Translation and back-translation made the interview guide available in both Maltese and English, and a readability test was carried out. The parents came alone for the interviews, and this gave them the chance to express themselves freely with less emotional barriers. This was the first original study of its kind in Malta.

Unfortunately, no standardised questionnaire or interview guide was found in the literature. Therefore, the researcher created the interview guide based on the research question, which was tested in a focus group, tested during an inter-rater exercise and assessed for readability.

\section{Conclusion}

This study reports that only one young person (out of 10 YP with ASD) carried out PA in line with WHO recommendations. More parents preferred group PA for their children, while more YP preferred individual PA. Parents explained that both group and individual PA have their benefits. Most parents felt misunderstood and burnt out, and felt that the country has to introduce more ASD-friendly sports facilities. Long hours on technological devices was also a major parental concern. Younger age and more severe ASD were associated with higher levels of PA, while older age and milder ASD were associated with higher use of technological devices.

Recommendations for practice include increasing the number of ASD-friendly sports facilities and staff training. Furthermore, sport mental health therapy services should be set up within the national health service by creating a multidisciplinary team of professionals. This should include parental support services to minimise the burden of care. PA programs in schools should run in parallel with such services as a means of preventive practice.

Recommendations from this study to the education services include an emphasis in sports mental health courses, public psychoeducation to minimise mental health stigma and the promotion of healthy use of technological devices to decrease the negative impact of screen time on YP.

\section{Declarations}

\section{Acknowledgement}

No funding was granted for the study. The authors would like to thank all the parents who participated for sharing their experiences in this study and all the doctors who contributed. The authors have declared that they have no competing or potential conflicts of interest.

\section{Ethics approval and consent to participate}

The application for an ethical opinion was submitted on the $24^{\text {th }}$ December 2017. A favourable ethical opinion (ref: HEC 14/17) was received from Health Ethics Committee (HEC), Ministry of Health - 
Government of Malta (date: $29^{\text {th }}$ January 2018). Research governance approval was granted by the Chairman of the Department of Psychiatry, Malta. Both verbal and written consent were obtained.

\section{Consent for publication}

Both verbal and written consent were obtained.

\section{Availability of data and materials}

The datasets generated and/or analysed during the current study are not publicly available due data protection reasons but are available from the corresponding author on reasonable request (completely anonymized data).

\section{Competing interests}

The authors have declared that they have no competing or potential conflicts of interest.

\section{Funding}

This study was self-funded. No funding was granted for this study.

\section{Authors Contributions}

The first and corresponding author was involved in the design of the study, analysis and interpretation of data, and writing up the report. The second author was involved in supervising the design of the study and substantively revising the reports. Both authors approved the submitted version and have agreed to be personally accountable for the authors' own contribution and to ensure that questions related to the accuracy or integrity of any part of the work, even ones in which the author was not personally involved, are appropriately investigated, resolved, and the resolution documented in the literature.

\section{Acknowledgements}

The authors would like to thank all the parents who participated for sharing their experiences in this study and all the doctors who contributed.

\section{References}

1. Alsehemi, M.A., Abdousaadah, M.M., Sairafi, R.A., Jan, M.M. (2017). Public awareness of autism spectrum disorder. Neurosciences (Riyadh) 22(3), pp. 213-215.

2. American Psychiatric Association. (2013). Diagnostic and Statistical Manual of Mental Disorders: DSM, 5th ed. Arlington, American Psychiatric Association.

3. Boreham, C., Riddoch, C. (2001). The physical activity, fitness and health of children. J Sports Sci 19(12), pp. 915-29. 
4. Braun, V., Clarke, V. (2006). Using thematic analysis in psychology. Qualitative Research in Psychology 3(2), pp. 77-101.

5. Czaya, S.J., Charness, N., Fisk, A.D., Hertzog, C., Nair, S.N., Rogers, W.A., Sharit, J. (2006). Factors Predicting the Use of Technology: Findings from the Centre for Research and Education on Aging and Technology Enhancement (CREATE). Psychol Aging 21(2), pp. 333-352.

6. Eime, R.M., Young, J.A., Harvey, J.T., Charity, M.J., Payne, W.R. (2013). A systematic review of the psychological and social benefits of participation in sport for children and adolescents: informing development of a conceptual model of health through sport. J. Behav. Nutr. Phys. Act. 10(98).

7. Godin, G., Shephard, R.J. (1997). Godin Leisure-Time Exercise Questionnaire. Medicine \& Science in Sports \& Exercise 26(6)

8. Obrusnikova, I., Miccinello, D.L. (2012). Parent Perceptions of Factors Influencing After-School Physical Activity of Children with Autism Spectrum Disorders. Adapt Phys Activ Q 29(1), pp. 63-80.

9. Pan, C.Y. (2009). Age, social engagement, and physical activity in children with autism spectrum disorders. Research in Autism Spectrum Disorders 3(10, PP. 22-31.

10. Pan, C.Y., Frey, G. (2006). Physical Activity Patterns in Youth with Autism Spectrum Disorders. J Autism Dev Disord 36(5), pp. 597-606.

11. Schultheis, S.F., Boswell, B.B., Decker, J. (2000). Successful Physical Activity Programming for Students with Autism. Focus Autism Other Dev Disab/15(3), 159-162.

12. Sport Malta, (2015). Directory. Retrieved from: https://www.sportmalta.org.mt/directory.

13. Stanish, H.I., Curtin, C., Must, A., Phillips, S. Maslin, M., Bandini, L.G. (2015). Enjoyment, Barriers, and Beliefs about Physical Activity among Adolescents With and Without Autism Spectrum Disorder. Adapt Phys Activ Q 32(4), pp. 302-331.

14. Stonerock, G.L., Hoffman, B.M., Smith, P.J., Blumenthal, J.A. (2015). Exercise as treatment for anxiety: Systematic review and analysis. Ann Behav Med 49(4), pp. 542-556.

15. Tureck, K., Matson, J.L., Cervantes, P., Turygin, N. (2015). Autism severity as a predictor of inattention and impulsivity in toddlers. Dev Neurorehabil 18(5), pp. 285-9.

16. Walker, A.N., Barry, T.D., Bader, S.H. (2010). Therapist and Parent Ratings of Changes in Adaptive Social Skills Following a Summer Treatment Camp for Children with Autism Spectrum Disorders: A Preliminary Study. Child and Youth Care Forum 39(5), pp. 305-322.

17. World Health Organisation, (2006). Physical Activity and Health in Europe. WHO Regional Office for Europe, Copenhagen, Denmark. ISBN 9289013877.

18. World Health Organisation, (2010). Global Recommendations on Physical Activity for Health. WHO Press, Geneva, Switzerland. ISBN 9789241599979.

19. Yonkman, J., Lawler, B., Talty, J., O’Neil, J., Bull, M. (2013). Safely transporting children with autism spectrum disorder: evaluation and intervention. Am J Occup Ther 67(6), pp. 711-6.

\section{Figures}




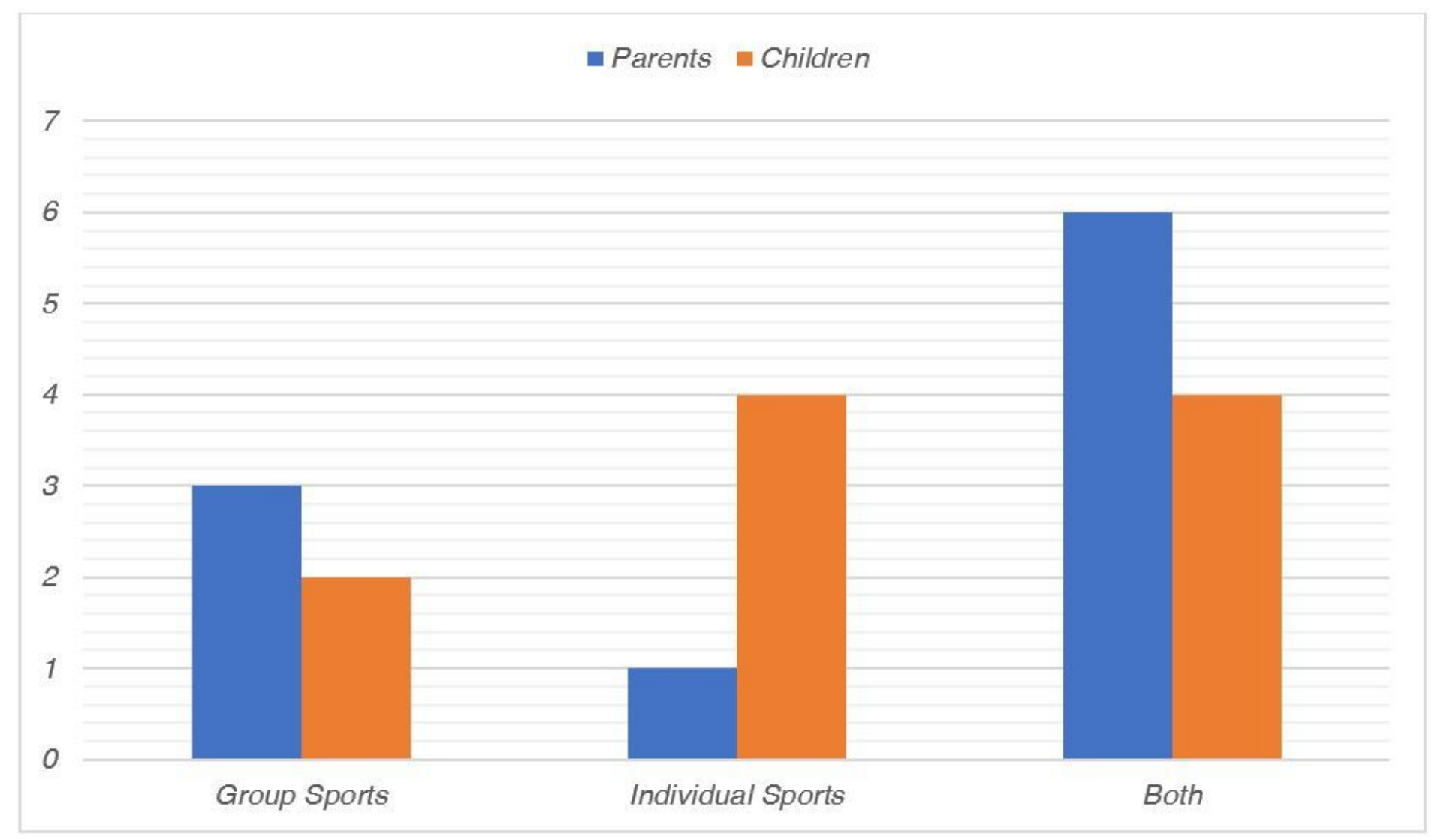

\section{Figure 1}

Sports preference (group vs individual) of Participants (parents) vs YP with ASD (children). 